\title{
Poder de mitigação da cinza de casca de arroz ao ataque por sulfatos em argamassas confeccionadas com resíduos de scheelita
}

\author{
Bark ash mitigation power of rice attacked by \\ sulfates in mortars made with scheelite residues
}

\begin{abstract}
Ana Luiza de Araújo ${ }^{1}$, Maria de Lourdes Xavier de França Neta ${ }^{1}$, Sâmea Valensca Alves Barros ${ }^{1}$, Gerbeson Carlos Batista Dantas ${ }^{1}$, Gelmires de Araújo Neves ${ }^{2}$
\end{abstract}

\footnotetext{
${ }^{1}$ Departamento de Engenharias, Universidade Federal Rural do Semi-árido, Rua Gamaliel Martins Bezerra, Alto da Alegria, CEP: 59515-000, Angicos, RN, Brasil.

${ }^{2}$ Unidade Acadêmica de Engenharia de Materiais, Universidade Federal de Campina Grande, Av. Aprígio Veloso, Bodocongó, CEP: 58429-900, Campina Grande, PB, Brasil.

E-mail: aluizaaraujo@hotmail.com,maria_xavieer@hotmail.com, sameavalensca@ufersa.edu.br, gerbeson_dantas@hotmail.com, gelmires.neves@ufcg.ed.br
}

\begin{abstract}
RESUMO
Nas últimas décadas, a exploração da mina de Scheelita, localizado em Currais Novos/RN, gerou um grande volume de resíduos sólidos que são descartados inadequadamente no meio ambiente, causando impactos ambientais negativos ao município. Uma das alternativas encontradas para minimizar esse problema é o uso desses resíduos em argamassas de revestimento, técnica utilizada para promover a destinação adequada dos resíduos sólidos oriundos da indústria da mineração. Entretanto, não há estudos consistentes sobre a durabilidade aos ataques químicos neste tipo de argamassas alternativas. Nesse contexto, este trabalho tem como objetivo verificar se a cinza da casca de arroz calcinada a $800{ }^{\circ} \mathrm{C}$ em substituição parcial ao cimento é capaz de mitigar o ataque químico por sulfato de sódio que ocorre em argamassas confeccionadas com resíduos de scheelita em substituição total ao agregado natural. Os resíduos de scheelita e a cinza da casca de arroz foram caracterizados por fluorescência de raios-x e difração de raios-x. O traço escolhido para realização da investigação foi 1:3, mais utilizado em chapisco, sendo o agregado convencional substituído totalmente pelo resíduo da scheelita e o cimento parcialmente pelo resíduo da cinza da casca de arroz calcinada a $800^{\circ} \mathrm{C}$. Após a definição do traço, moldou-se os corpos de prova de argamassa para submeter ao ataque químico conforme a norma ABNT NBR 13583. Os resultados indicaram que o teor de substituição do cimento pela cinza de casca de arroz calcinada a $800^{\circ} \mathrm{C}$ não foi capaz de mitigar o ataque químico, pois a expansão das barras de argamassa ultrapassou o limite estabelecido $(0,06 \%)$ pela norma da ASTM C 452. Entretanto, as expansões não foram suficientes para causar perda da resistência mecânica dos corpos de prova para o período de ataque.
\end{abstract}

Palavras-chave: Adições minerais. Material pozolânico. Durabilidade. Reatividade química. Argamassas alternativas.

\begin{abstract}
In the last decades, the exploration of the Scheelita mine, located in Currais Novos/RN, generated a large volume of solid waste that is improperly disposed of in the environment, causing negative environmental impacts to the municipality. One of the alternatives found to minimize this problem is the use of these residues in coating mortars, a technique used to promote the proper destination of solid wastes from the mining industry. However, there are no consistent studies on the durability of chemical attacks in this type of alternative mortar. In context, this work aims to verify if the rice husk ash calcined at $800{ }^{\circ} \mathrm{C}$ in partial replacement to cement is able to mitigate the chemical attack by sodium sulfate that occurs in mortars made with scheelite residues in total replacement to the natural aggregate. Scheelite residues and rice husk ash were characterized by $\mathrm{x}$-ray fluorescence and $\mathrm{x}$-ray diffraction. The dosage chosen to carry out the investigation was $1: 3$, most used in base mortar, with the conventional aggregate replaced entirely by scheelite waste and cement partial-
\end{abstract}


ly by rice husk ash calcined at $800^{\circ} \mathrm{C}$. After defining the dosage, the mortar specimens were molded to be subjected to chemical attack in accordance with the ABNT NBR 13583 standard. The results indicated that the cement substitution content by rice husk ash calcined at $800^{\circ} \mathrm{C}$ was not to mitigate the chemical attack, since the expansion of the mortar bars exceeded the limit established $(0.06 \%)$ by the ASTM C 452 standard. However, the expansions were not sufficient to cause loss of the mechanical resistance of the specimens for the attack period.

Keywords: Supplementary cementitious material. Pozzolanic material. Durability. Chemical reactivity. Alternative mortars

\section{INTRODUÇÃO}

O estado do Rio Grande do Norte é um dos maiores detentores de jazidas de minério do Brasil. Dentre estas, destacam-se os jazimentos de scheelita, localizados no município de Currais Novos/RN. Apesar da importância econômica, esta exploração tem causado um impasse ambiental dado o volume de resíduos gerados que recobrem uma área de $121.500 \mathrm{~m}^{2}$, totalizando 3.110 .400 toneladas de resíduos (2002), como também pela sua destinação final ambientalmente inadequada [1-2].

As pilhas de resíduos gerados durante a exploração são dispostas a céu aberto e em contato direto com a superfície do solo. Segundo o Instituto Brasileiro de Mineração (IBRAM) [3] é possível que esses materiais possam apresentar valor econômico para segmentos da indústria e, além disso, possam ser utilizados em materiais alternativos, proporcionando uma gestão mais adequada dos resíduos sólidos gerados [4].

Desta forma, a construção civil tem utilizado o resíduo da mineração de scheelita como agregado na confecção de concretos, argamassas, pavimentos e na produção de blocos cerâmicos [5-7]. No entanto, não há estudos que avaliem a viabilidade técnica destes compósitos cimentícios incorporados com scheelita quanto à sua durabilidade, sobretudo, com enfoque nos ataques químicos por sulfatos.

Os ataques químicos por sulfatos são um dos que mais afetam a durabilidade dos materiais de matrizes cimentícias. Os íons sulfatos $\left(\mathrm{SO}_{4}{ }^{-2}\right)$ reagem com a portlandita $\left(\mathrm{Ca}(\mathrm{OH})_{2}\right)$, silicato de cálcio hidratado $\left(3 \mathrm{CaO} .2 \mathrm{SiO}_{2} \cdot 3 \mathrm{H}_{2} \mathrm{O}\right)$ e o monossulfoaluminato de cálcio hidratado $\left(\mathrm{C}_{3} \mathrm{~A} . \mathrm{CaSO}_{4} \cdot 14 \mathrm{H}_{2} \mathrm{O}\right)$ presentes no cimento Portland, formando gipsita $\left(\mathrm{CaSO}_{4} .2 \mathrm{H}_{2} \mathrm{O}\right)$, etringita secundária $\left(\mathrm{C}_{3} \mathrm{~A} .3 \mathrm{CaSO}_{4} .33 \mathrm{H}_{2} \mathrm{O}\right)$ e a taumasita $(\mathrm{Ca}-$ $\mathrm{SiO}_{3} \cdot \mathrm{CaCO}_{3} \cdot \mathrm{CaSO}_{4} \cdot 15 \mathrm{H}_{2} \mathrm{O}$ ) [8-9]. Estes compostos alteram a estrutura porosa das argamassas devido a pressão da cristalização dos sais formados, causando expansão ou contração volumétrica da estrutura, o que pode causar fissuras e degradação mecânica [10-12].

As adições minerais em argamassas podem influenciar decisivamente no comportamento destas quando em ambiente sulfatado devido às alterações que são desencadeadas na porosidade do material, como também, pela constituição química da adição mineral que pode ou não favorecer o desenvolvimento das reações de sulfato [8-12].

Uma das alternativas frequentemente utilizadas para aumentar a resistência das argamassas aos íons sulfatos é adicionar pozolanas na mistura. Isso se justifica por que os materiais pozolânicos reduzem a porosidade do compósito cimentício e reagem rapidamente com os constituintes anidros do cimento, bloqueando a reconversão de minerais expansivos no interior do material [11].

Dentre os materiais pozolânicos conhecidos, destaca-se a cinza da casca de arroz (CCA). A CCA é classificada como pozolana artificial, pois é obtida através de processos industriais. No entanto, a característica determinante para ser considerada pozolana está associada a diferentes fatores como a composição química da casca, assim como a condição de queima adotada [13].

Neste contexto, considerando ausência de estudos que investigam a durabilidade de argamassas preparadas com scheelita submetidas ao ataque de sulfatos, o objetivo deste trabalho é verificar se argamassas confeccionadas com resíduo scheelita em substituição total ao agregado natural e cinza da casca de arroz calcinada a $800^{\circ} \mathrm{C}$ em substituição parcial do cimento são susceptíveis a ataque de sulfatos.

\section{MATERIAIS E MÉTODOS}

\subsection{Materiais}

Os materiais convencionais utilizados neste trabalho foram: Cimento Portland CP V ARI MAX por não conter pozolana em sua composição química (Tabela 1); cal hidratada CH-I, localizada em Limoeiro do Norte $\mathrm{CE}$, escolhida por apresentar elevado teor de pureza e ter na sua composição química $87 \%$ portlandita $\left(\mathrm{Ca}(\mathrm{OH})_{2}\right), 11 \%$ calcita $\left(\mathrm{CaCO}_{3}\right)$ e $2 \%$ de água livre e cal livre em sua composição. 
Tabela 1: Composição química do cimento Portland

\begin{tabular}{|c|c|c|c|c|c|c|c|c|c|c|c|c|}
\hline ÓxIDOS & $\begin{array}{c}\mathrm{CaO} \\
(\%)\end{array}$ & $\begin{array}{c}\mathrm{SiO}_{2} \\
(\%)\end{array}$ & $\begin{array}{c}\text { MgO } \\
\text { (\%) }\end{array}$ & $\begin{array}{c}\mathrm{Al}_{2} \mathrm{O}_{3} \\
(\%)\end{array}$ & $\begin{array}{c}\mathrm{Fe}_{2} \mathrm{O}_{3} \\
(\%)\end{array}$ & $\begin{array}{l}\mathrm{SO}_{3} \\
(\%)\end{array}$ & $\begin{array}{l}\mathrm{K}_{2} \mathrm{O} \\
(\%)\end{array}$ & $\begin{array}{c}\mathrm{TiO}_{2} \\
(\%)\end{array}$ & $\begin{array}{c}\mathrm{P}_{2} \mathrm{O}_{5} \\
(\%)\end{array}$ & $\begin{array}{l}00^{a} \\
(\%)\end{array}$ & $\begin{array}{l}\mathbf{P F}^{\mathbf{b}} \\
(\%)\end{array}$ & $\begin{array}{r}C_{3} A^{c} \\
(\%)\end{array}$ \\
\hline Teor & 61,35 & 19,1 & 1,33 & 5,33 & 4,1 & 4,87 & 1,04 & 0,5 & 0,0 & 0,0 & 2,2 & 7,18 \\
\hline
\end{tabular}

Como material alternativo foi utilizado o resíduo gerado na extração de scheelita e a cinza da casca de arroz (CCA) obtida da calcinação das cascas de arroz. O resíduo de scheelita foi denominado nesta pesquisa de Areia de scheelita (AS), sendo coletado na granulometria média e cedido. A CCA foi obtida no município de Caicó/RN. O agregado convencional foi substituído totalmente pela AS e o cimento pelas porcentagens de $15 \%$ e $25 \%$ pela CCA calcinada a $800^{\circ} \mathrm{C}$.

\subsection{Métodos}

\subsubsection{Caracterização física e química do resíduo de scheelita (AS)}

A caracterização física do agregado estudado foi realizada com a determinação dos seguintes parâmetros: análise granulométrica por peneiramento; massa unitária e teor de material pulverulento. O peneiramento ocorreu utilizando a série normal de peneiras, seguindo os procedimentos da norma NBR NM 248 [14]. A composição química foi determinada por espectrometria de fluorescência de raios x, utilizando o equipamento EDX 720 da Shimadzu. A composição mineralógica foi caracterizada por meio da difração de raios X, utilizando o equipamento Difratômetro Shimadzu XRD-6000 com radiação CuKa, tensão de $40 \mathrm{kV}$, corrente de $30 \mathrm{~mA}$, modo de escaneamento por passos (fixed time scan), com passo de 0,02 e tempo de contagem de $0,6 \mathrm{~s}$, com ângulo $2 \theta$ percorrido de $5^{\circ}$ a $60^{\circ}$.

\subsubsection{Beneficiamento e caracterização química-mineralógica da CCA}

A casca de arroz passou por queima em olaria para retirada do teor de carbono, em seguida, realizou-se a calcinação da cinza resultante, em mufla a temperatura de $800^{\circ} \mathrm{C}$ por duas horas, em atmosfera oxidante. Após o processo de calcinação, o material passou em peneira ABNT nº $200(0,074 \mathrm{~mm})$. A composição química e mineralógica foram determinadas por espectrometria de fluorescência de raios-x e difração de raios-X, respectivamente, conforme procedido para o resíduo da scheelita.

\subsubsection{Preparação das Argamassas}

Os corpos de prova (CP's) foram moldados com a incorporação da AS em substituição total ao agregado convencional e substituição parcial ao cimento por CCA nas porcentagens de $15 \%$ e $25 \%$, além dos corpos de prova de referência (sem substituição de CCA) conforme as prescrições das normas da ABNT NBR 13583 [15] e NBR 7215 [16]. Logo, moldou-se no traço 1:3 em massa doze CP's prismáticos com dimensões (25x25x285) mm para determinação da variação dimensional das barras de argamassas expostas a solução de sulfato de sódio e doze CP's cilíndricos nas dimensões $(50 \times 100) \mathrm{mm}$ para verificação da ocorrência da degradação. Posteriormente, os CP's foram curados em câmara úmida com $100 \%$ de umidade relativa por um período de 48 horas. Por fim, colocou-se 6 CP's imersos em água destilada por (42 dias) e 6 CP's em solução de sulfato de sódio por (42 dias).

\subsubsection{Determinação da variação dimensional de barras de argamassas de cimento Portland expostas à solução de sulfato de sódio}

A ocorrência do ataque por sulfato nas amostras de argamassas confeccionadas com resíduos da mineração de scheelita em substituição total ao agregado natural foi avaliada pela sua variação dimensional quando imersas em solução de sulfato de sódio, conforme metodologia sugerida pela norma ABNT NBR 13583 [15]. Os CP's ficaram imersos por 42 dias em solução de sulfato de sódio, sendo realizadas medições em relógio comparador aos 7, 14, 28 e 42 dias. O valor utilizado para avaliar a ocorrência do ataque químico por sulfato de sódio foi o determinado pela ASTM C 452 [17]. 


\subsubsection{Determinação da resistência à compressão simples (RCS)}

A RCS foi obtida conforme a norma da ABNT NBR 7215 [16], a partir da média aritmética simples dos valores obtidos para três CP's $(n=3)$ cilíndricos com dimensões $(50 x 100) \mathrm{mm}$ para o traço 1:3. O equipamento utilizado para romper os CP's foi a Máquina Universal Emic SSH300, célula Trd 30 com velocidade de carga de $0,25 \pm 0,05 \mathrm{MPa} / \mathrm{s}$

\section{RESULTADOS E DISCUSSÃO}

A Tabela 2 apresenta as propriedades físicas determinadas para o agregado oriundo da scheelita (AS). Verifica-se que a AS pode ser classificada como agregado normal, conforme a classificação proposta por Bauer [18]. Ainda de acordo com o autor, esses agregados são ideais para uso em argamassa, pois o valor da massa unitária apresentada por esse resíduo se encontra na faixa de valor $1 \leq \boldsymbol{\gamma} \leq 2 \mathrm{~g} / \mathrm{cm}^{3}$. A AS apresentou módulo de finura de 2,4, sendo classificado como areia de granulometria média [18].

Tabela 2: Propriedades físicas da Areia de scheelita

\begin{tabular}{ccc}
\hline & ENSAIO & AS \\
\hline \multicolumn{2}{c}{ Massa unitária ou aparente $\left(\mathrm{g} / \mathrm{cm}^{3}\right)$} & 1,69 \\
\hline \multicolumn{2}{c}{ Teor de materiais pulverulentos $(\%)$} & 1,4 \\
\hline \multirow{2}{*}{ Granulometria } & Diâmetro máximo & $2,37 \mathrm{~mm}$ \\
\cline { 2 - 3 } & Módulo de finura & 2,4 \\
\hline
\end{tabular}

A Figura 1 apresenta a curva granulométrica da AS. De acordo com comportamento dessa curva, constatou-se que AS tem granulometria graduada, fato que proporciona maior compacidade das argamassas. De acordo com a distribuição dos grãos observados na curva granulométrica (Figura 1), percebe-se que AS pode ser utilizada na confecção de argamassas por apresentar grãos mistos e bem graduados.

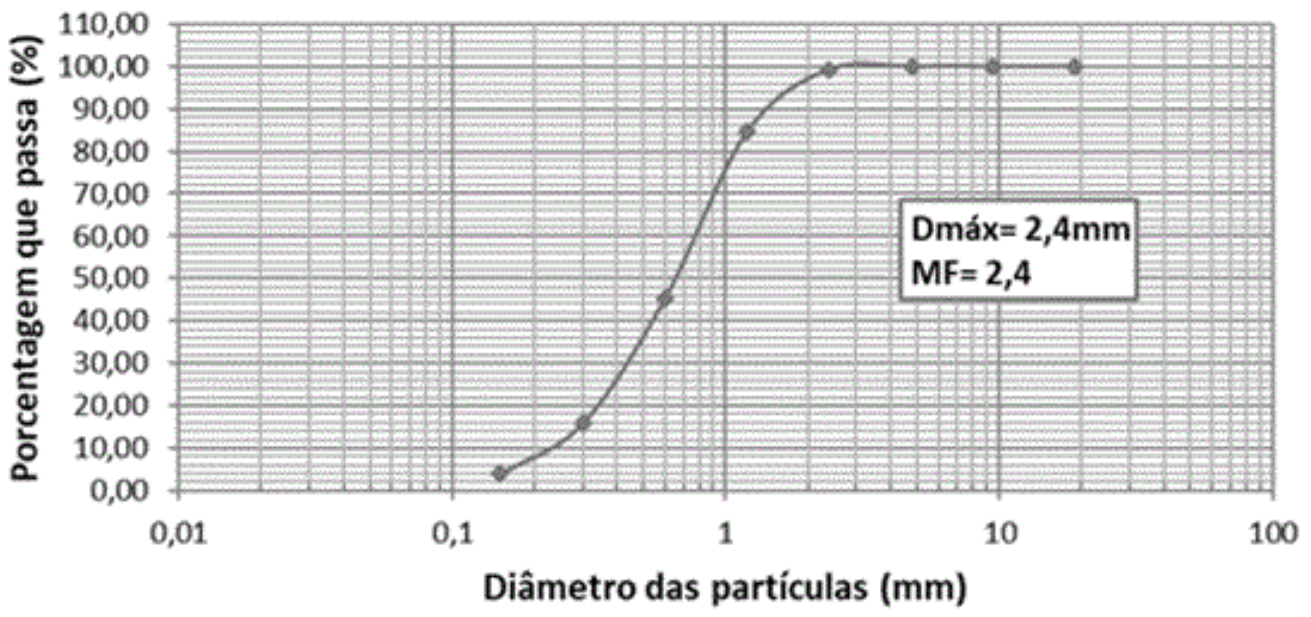

Figura 1: Curva granulométrica da AS.

A composição química da AS e da CCA estão apresentadas na Tabela 3. A areia de scheelita apresentou valores elevados de óxido de cálcio $(\mathrm{CaO})$ e de sílica $\left(\mathrm{SiO}_{2}\right)$. O elevado teor de perda ao fogo a $1000{ }^{\circ} \mathrm{C}$ da AS é justificado pela presença da fase mineralógica calcita $\left(\mathrm{CaCO}_{3}\right)$ que nessa temperatura se decompõe em óxido de cálcio e gás carbônico $\left(\mathrm{CO}_{2}\right)$. Ainda de acordo com a Tabela 3, observa-se que a CCA é composta predominantemente por sílica $\left(\mathrm{SiO}_{2}\right)$, seguido de traços de óxido de potássio, alumínio e cálcio. Esse resultado é interessante, por que materiais com elevado teor de $\mathrm{SiO}_{2}, \mathrm{Al}_{2} \mathrm{O}_{3}$ e/ou $\mathrm{Fe}_{2} \mathrm{O}_{3}(>80 \%)$ apresentam composição química favorável para serem utilizadas em argamassas, à medida que a sílica for amorfa, comportando-se como um material pozolânico. Resultados similares foram relatados por outros autores [19-20]. 
Tabela 3: Composição química da CCA calcinada a $800^{\circ} \mathrm{C}$ e da AS

\begin{tabular}{ccc}
\hline ÓXIDOS (\%) & CCA $_{\mathbf{~ 8 0 0}} \mathbf{C}$ & AS \\
\hline $\mathrm{PF}$ & - & 15,74 \\
$\mathrm{SiO}_{2}$ & 91,55 & 21,76 \\
$\mathrm{CaO}$ & 1,65 & 38,46 \\
$\mathrm{~K}_{2} \mathrm{O}$ & 2,45 & 0,55 \\
$\mathrm{P}_{2} \mathrm{O}_{5}$ & 0,79 & - \\
$\mathrm{Al}_{2} \mathrm{O}_{3}$ & 2,11 & 7,62 \\
$\mathrm{MgO}$ & 0,47 & 3,33 \\
$\mathrm{SO}_{3}$ & 0,55 & - \\
$\mathrm{Fe}_{2} \mathrm{O}_{3}$ & 0,25 & 9,81 \\
Outros óxidos & 0,18 & 2,73 \\
\hline
\end{tabular}

Os difratogramas de raios-x da AS e da CCA calcinada a $800^{\circ} \mathrm{C}$ são mostrados na Figura 2. Com base nos picos difratométricos da CCA (Figura 2a), observa-se a presença de duas fases mineralógicas atribuídas a fases cristalinas da sílica: uma na sua estrutura mais estável que é o quarzto ( $\mathrm{SiO}_{2}$, ICDD 00-33-1161) e a segunda na estrutura da cristobalita $\left(\mathrm{SiO}_{2}, \mathrm{ICDD}\right.$ 00-082-0512). Além disso, observa-se uma região de halos amorfos atribuídas a presença de sílica na forma amorfa. Esse resultado justifica o elevado teor de sílica evidenciado na composição química da Tabela 3, bem como, indica um comportamento pozolânico da CCA [21]. O difratograma da AS (Figura 2b) evidencia três fases mineralógicas: mica $(\mathrm{K}(\mathrm{Mg}$, $\mathrm{Fe})_{3}\left(\mathrm{Si}_{3} \mathrm{Al}\right) \mathrm{O} 10(\mathrm{OH})_{2}, \mathrm{ICDD}$ 00-083-1808), calcita $\left(\mathrm{CaCO}_{3}, \mathrm{ICDD}\right.$ 00- 005-0586) e quartzo $\left(\mathrm{SiO}_{2}\right.$, ICDD 0033-1161). Esses resultados corroboram com aqueles observados na composição química da Tabela 3 . Os elevados teores de óxido de cálcio são atribuídas à reflexão principal da calcita situada entre $27,50<\theta<30^{\circ}$. $\mathrm{O}$ teor de sílica na AS é atribuída as presenças da mica e do quartzo, conforme observado no difratograma (Figura $2 b$ ).

a)

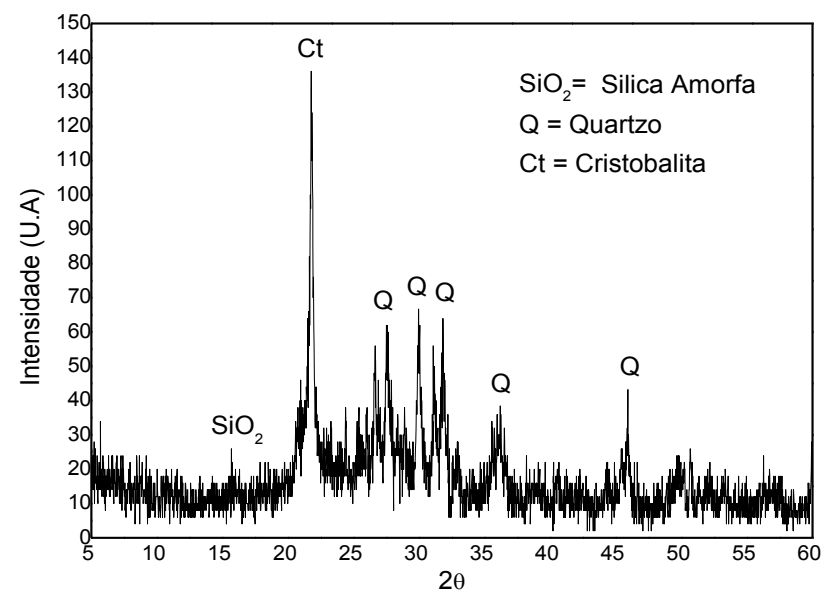

b)

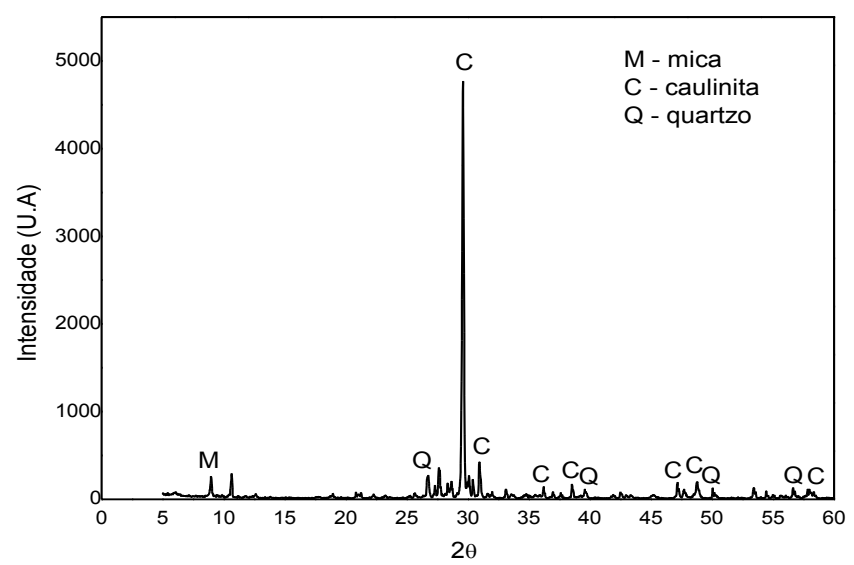

Figura 2: Difratogramas de raios-x, a) $\mathrm{CCA} 800{ }^{\circ} \mathrm{C}$ e b) $\mathrm{AS}$ 
As Figuras 3a, 3b e 3c ilustram as curvas das expansões obtidas pelas argamassas de referência e as confeccionadas com $15 \%$ e $25 \%$, respectivamente, de substituição parcial do cimento Portland pela CCA calcinada a $800^{\circ} \mathrm{C}$ e $100 \%$ de AS quando imersas em solução de sulfato de sódio ao longo dos 42 dias de exposição. Com base nos resultados, as argamassas de referência incorporadas com resíduos de scheelita confeccionadas no traço 1:3 com 100\% AS e sem nenhuma adição de CCA sofreram uma expansão de $0,083 \%$ aos 42 dias. Logo, constata-se que este traço foi reativo ao ataque por sulfato, pois o valor obtido aos 42 dias de imersão foi maior que o estabelecido pela norma ASTM C 452 [17] (0,06\%). As argamassas confeccionadas com 15\% de CCA (Figura 3b) também apresentaram reatividade, pois aos $42 \mathrm{~d}$ de exposição ao sulfato de sódio, a expansão também foi superior ao limite de $0,06 \%$ estabelecido pela norma ASTM C 452 [17], fato também constatado pelas argamassas da Figura 3c. Então, ao comparar as argamassas com substituição de CCA a argamassas de referência (Figura 3a) verifica-se que as argamassas estudadas também não são resistentes ao ataque por sulfato quando o método de avaliação aplicado for a variação dimensional dessas barras imersas em solução de sulfato de sódio, estabelecido pela norma da ABNT NBR 13583 [15] e adotado o limite estabelecido pela norma da ASTM C 452 [17].

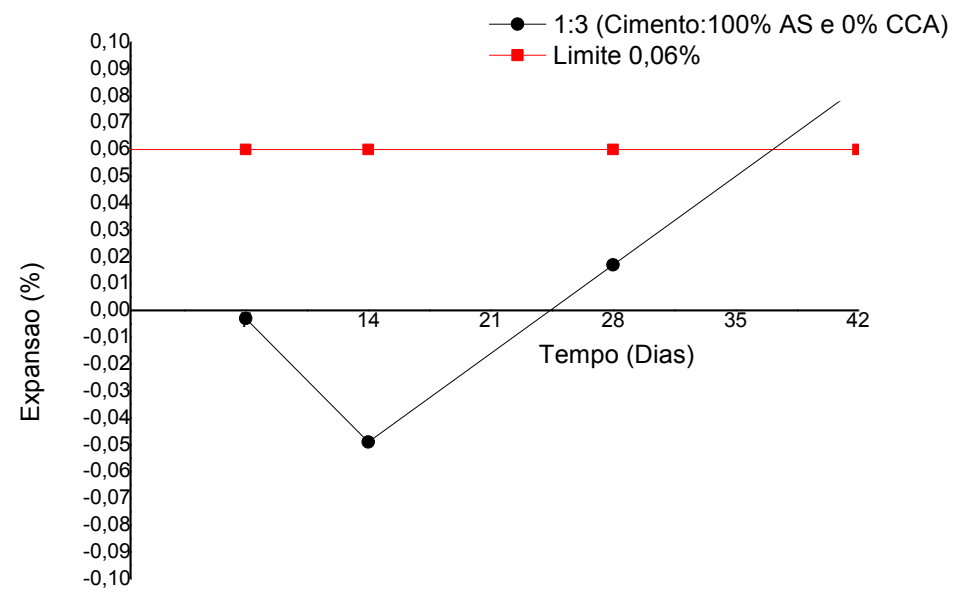

a)

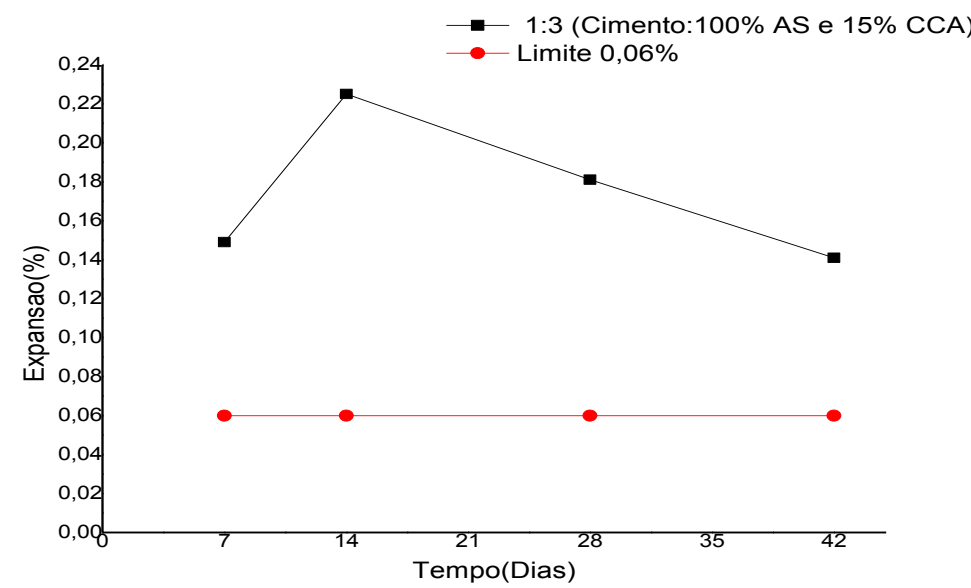

b) 


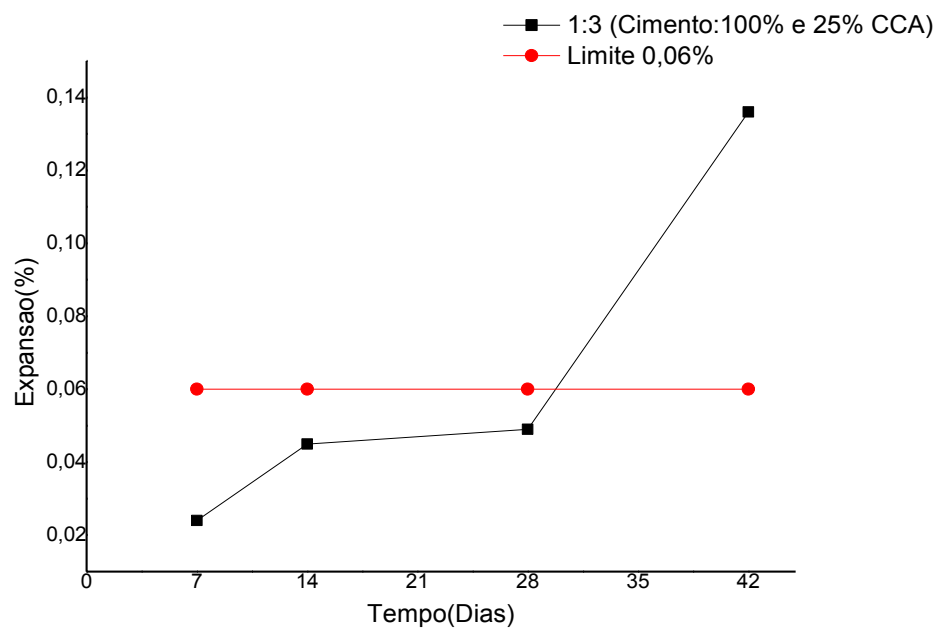

c)

Figura 3: Expansões dimensionais ao longo dos 42 dias de imersão em solução de sulfato de sódio, a) Expansão para o traço 1:3 com 0\% de substituição do cimento pela CCA (argamassa de referência), b) Expansão para o traço $1: 3$ com $15 \%$ de substituição do cimento pela CCA calcinada a $800^{\circ} \mathrm{C}$, b) Expansão para o traço $1: 3$ com $25 \%$ de substituição do cimento pela CCA calcinada a $800^{\circ} \mathrm{C}$.

Verifica-se que na argamassa de referência e na que apresenta 25\% de CCA ocorreu entre o sétimo e décimo quarto dia retração provocada pelos íons de sulfato e a partir dessa idade começaram a se expandir, provavelmente devido ao processo de formação da etringita (elemento expansivo) que acontece quando há reação dos íons de sulfato com o aluminato tricálcico do cimento ou com a alumina do agregado. Enquanto, na argamassa com 15\% não ocorreu retração só expansão.

A Tabela 4 apresenta os valores obtidos para resistência à compressão simples dos corpos de prova após imersão em água destilada (42 dias) e em solução de sulfato de sódio (42 dias).

Tabela 4: Valores de resistência à compressão simples dos CP's após ataque por sulfato.

\begin{tabular}{cccc}
\hline $\begin{array}{c}\text { SUBSTITUIÇÃO } \\
\text { (\% DE CCA) }\end{array}$ & $\begin{array}{c}\text { RCS 42 DIAS DE IMER- } \\
\text { SÃo EM ÁGUA (Mpa }\end{array}$ & $\begin{array}{c}\text { RCS APÓS 42 DIAS DE IMERSÃo EM } \\
\text { SOLUÇÃO DE SULFATO DE SÓDIO (Mpa) }\end{array}$ & VARIAÇÃO \\
\hline $0 \%$ & $13,46 \pm 0,18$ & $13,23 \pm 0,66$ & $-1,70 \%$ \\
\hline $15 \%$ & $12,22 \pm 2,45$ & $12,21 \pm 0,98$ & $-0,08 \%$ \\
\hline $25 \%$ & $13,44 \pm 1,19$ & $13,39 \pm 1,99$ & $-0,37 \%$ \\
\hline
\end{tabular}

Com base nos valores obtidos, verifica-se que as variações da resistência mecânica dos CP imersos em água e os CP imersos em solução de sulfato de sódio não foram significativas e portanto, não caracterizam ocorrência de degradação mecânica das argamassas. Portanto, apesar dos resultados da expansão (Figura 3) indicarem reatividade das argamassas ao sulfato de sódio, não foram suficientes para degradar mecanicamente os corpos de prova para a idade de exposição aos íons.

\section{CONCLUSÃO}

A partir dos resultados obtidos neste trabalho, conclui-se que:

As barras de argamassas confeccionadas com substituições parciais de $15 \%$ e $25 \%$ do cimento Portland pela CCA calcinada a $800^{\circ} \mathrm{C}$ e substituição total do agregado natural pela AS são suscetíveis ao ataque por sulfato de sódio.

$\mathrm{O}$ agregado AS pode ser considerado reativo à medida que ocorreu a ataque por sulfato de sódio e apresenta na sua constituição química um teor considerável de alumina que expansões obtidas nos levam a acreditar que se formou etringita, que é um elemento expansivo que pode desencadear tanto a retração como a expansão. 
As argamassas estudadas não apresentam durabilidade para serem utilizadas em ambientes agressivos, ricos em sulfatos porque o agregado de Scheelita apresenta elementos químicos reativos com os íons de sulfato.

A CCA calcinada a $800^{\circ} \mathrm{C}$ nas proporções de 15 e $25 \%$ de substituição ao cimento não conseguem inibir $\mathrm{o}$ ataque por sulfato em argamassas confeccionadas com AS em substituição total ao agregado natural. $\mathrm{O}$ teor de $25 \%$ apresentou um comportamento mais próximo ao da argamassa de referência e o de $15 \%$ valores de expansão maiores, que demonstram que a CCA calcinada a $800^{\circ} \mathrm{C}$ não foi capaz de mitigar o ataque.

\section{BIBLIOGRAFIA}

[1] PETTA, R.A., SINDERN, S., SOUZA, R.F., et al., "Influence of mining activity on the downstream sediments of scheelite mines in Currais Novos (NE Brazil)". Environmental Earth Sciences, v.72, pp.1843-1852, Feb.2014.

[2] MOREIRA, M.S., MANHÃES, J.P.V.T., HOLANDA, J.N.F. "Processing of red ceramic using ornamental rock powder waste". Journal of 'Materials Processing Technology, v.196, pp. 88-93, Feb.2008.

[3] INSTITUTO BRASILEIRO DE MINERAÇÃO (IBRAM). www.ibram.org.br. Acesso em janeiro de 2020.

[4] BARROS, S.V.A., DANTAS, G.C.B., SILVA, A.S., et al., "Behavior of mortar blended with quartzite residues when subjected to natural aging". Revista Eletrônica em Gestão, Educação e Tecnologia Ambiental, v. 1, pp. 1-10, Feb 2020.

[5] MACHADO, T.G. "Estudo da adição de resíduo de scheelite em matriz cerâmica: formulação, propriedades físicas e microestrutura". Tese de D. Sc., UFRN, Natal, RN, Brasil, 2012.

[6] PAIVA, E.H.G. "Avaliação do concreto de cimento Portland com resíduo da produção de scheelita em substituição ao agregado miúdo”. Dissertação de M. Sc., UFRN, Natal, RN, Brasil, 2013.

[7] MEDEIROS, M. "Estudo de argamassas de revestimento com resíduo de scheelita". Dissertação de M. Sc., UFRN, Natal, RN, Brasil, 2016.

[8] HOPPE FILHO, J., SOUZA, D.J., MEDEIROS, M.H.F., et al., “Ataque de matrizes cimentícias por sulfato de sódio: adições minerais como agentes mitigadores”. Cerâmica, v.61, pp.168-177, Feb.2015.

[9] OUYANG, W., CHEN, J.K., JIANG, M.Q. "Evolution of surface hardness of concrete under sulfate attack". Construction and Building Materials, v.53, pp. 419-424, Feb.2014.

[10] ROZIÈRE, E., LOUKILI, A., EL HACHEM, R., et al., "Durability of concrete exposed to leaching and external sulphate attacks". Cement and Concrete Research, v.39, pp.1188- 1198, Feb.2009.

[11] MEHTA, P. K.., MONTEIRO, P.J.M. “Concreto: Microestrutura, Propriedades e Materiais”. 3 ed. São Paulo, SP, IBRACON, 2008.

[12] BARROS, S.V.A., NEVES, G.A., MENEZES, R.R.; et al., "Mechanical behavior and durability of mortars with quartzite and Portland cement after sulfate attack”. Matéria, v.24, n.4, pp.1-9, Feb.2019.

[13] CORDEIRO, L.N.P., MASUERO, A.B., DAL MOLIN, D.C.C. "Análise do potencial pozolânico da cinza de casca de arroz (CCA) através da técnica de Refinamento de Rietveld”. Matéria, v.19, n.2, pp.150158, Feb.2014.

[14] ASSOCIAÇÃO BRASILEIRA DE NORMAS TÉCNICAS. NBR NM 248: “Agregados - Determinação da composição granulométrica”. Rio de Janeiro: ABNT, 2003.

[15] ASSOCIAÇÃO BRASILEIRA DE NORMAS TÉCNICAS (ABNT). NBR 13583: Cimento PortlandDeterminação da variação dimensional de barras de argamassa de cimento Portland expostas à solução de sulfato de sódio- Especificação. Rio de Janeiro: ABNT, 2014.

[16] ASSOCIAÇÃO BRASILEIRA DE NORMAS TÉCNICAS. NBR 7215: "Cimento Portland- Determinação da resistência à compressão". Rio de Janeiro: ABNT, 2019.

[17] AMERICAN SOCIETY FOR TESTING AND MATERIALS. ASTM C 452: "Standard Test Method for Potential Expansion of Portland-Cement Mortars Exposed to Sulfate", 2002.

[18] BAUER, L.A.F. "Materiais de construção". 1ªed. Rio de Janeiro: Livros Técnicos e Científicos, v .1, p.435, 1994.

[19] XIONG, L., SEKIYA, E.H., SUJARIDWORAKUN, P., et al. "Burning Temperature Dependence of Rice Husk Ashes in Structure and Property”. Journal of Metals, Materials and Minerals, v.19, n. 2, pp.95-99, Feb. 2009.

[20] SOLTANI, N., BAHRAMI, A., PECH-CANUL, M.I., et al. "Review on the physicochemical treatments of rice husk for production of advanced materials". Chemical Engineering Journal, v. 264, pp. 899-935, Feb. 2015.

[21] SILVA, J.O., BARROS, S.V.A., DANTAS, G.C.B., et al., "Caracterização da cinza da casca de arroz visando aplicação na confecção de materiais alternativos para construção civil". Revista de Ciências Ambientais, v. 14, p. 17-23, Feb.2020. 


\section{ORCID}

Ana Luiza de Araújo

Maria de Lourdes Xavier de França Neta

Sâmea Valensca Alves Barros

Gerbeson Carlos Batista Dantas

Gelmires de Araújo Neves https://orcid.org/0000-0003-0512-2747

https://orcid.org/0000-0002-4736-857X

http://orcid.org/0000-0002-9035-486X

http://orcid.org/0000-0002-6662-5789

http://orcid.org/0000-0002-2900-1600 